\title{
LOS TEXTOS ESCOLARES EN CONFLICTO CON LA SUBALTERNIDAD: LA GUERRA DEL PACÍFICO EN LAS AULAS
}

\author{
THE SCHOOL BOOKS IN CONFLICT WITH SUBALTERN: \\ PACIFIC WAR IN THE CLASSROOM
}

\author{
José Chaupis Torres*
}

\begin{abstract}
La investigación tiene como objetivo el estudio de los manuales escolares, para comprender la forma en que han sido presentados los actores subalternos en la guerra del Pacífico. Los textos escolares seleccionados son de las editoriales Santillana y Norma, que tienen una mayor participación en los colegios en el área de Historia, Geografía y Economía. Analizaremos los manuales escolares tomando en cuenta la intencionalidad de las editoriales, vinculándola con la reglamentación de los enunciados curriculares, la intervención estatal administrativa y política. Estudiaremos también la sistematicidad en la exposición de los contenidos, tomando en consideración la combinación de textos, imágenes y fuentes, la presencia de recursos didácticos manifiestos mediante el desarrollo de actividades.

Complementariamente a estos objetivos articularemos el discurso difundido por los textos escolares con la producción historiográfica más reciente, para observar la distancia que existe entre una y otra, brecha que al ser tan grande ha dejado de lado a los actores subalternos impidiendo que se convierta desde abajo en factor para la integración de ambos países, por ello habría que pensar en una debida contextualización y una reconceptualización histórica discursiva de esta guerra desde la subalternidad.

Palabras claves: Textos escolares, guerra del Pacífico, actores subalternos, historiografía, competencias educativas.
\end{abstract}

The research aims to study school books, to understand how have been presented subaltern actors in the Pacific War. School books selected area of Santillana and Norma publishers, which have higher participation in schools in the area of History, Geography and Economics. We will analyze school books taking into account intention of publishing as related to regulations of curriculum statements, state administrative and political intervention. We will also study the consistency in the presentation of the contents, taking into account combination of text, images and fonts, the presence of overt teaching resources through the development of activities. Complementary to these objectives, we will articulate the speech broadcast on school books with the most recent historiographical production, in order to observe the gap between them, gap being so great has bypassed subaltern actors preventing it from becoming bottom a factor for the integration of both countries. So, we should think about a proper and discursive reconceptualization of this war from the subaltern.

Key words: School books, Pacific War, subaltern actors, historiography, educational skills.

\section{Introducción}

El estudio de los textos escolares en los últimos años ha recibido el interés de diversos especialistas (historiadores, educadores, comunicadores). Esto es importante en la medida en que el manual escolar es una obra destinada a la enseñanza-aprendizaje, teniendo como política de Estado lograr aprendizajes significativos mediante el desarrollo de competencias, capacidades, conocimientos y actitudes, que permitan la construcción y consolidación de la identidad social y cultural de los estudiantes. La presente investigación tiene como objetivo el estudio de los manuales escolares, para comprender la forma en que han sido presentados los actores subalternos en la guerra del Pacífico a partir de un análisis de contenido, tomando en consideración la competencia de manejo de información que implica la forma en la que han seleccionado, organizado, interpretado y evaluado la información (Ministerios de Educación del Perú [MINEDU] 2010: 12-13). Los textos escolares seleccionados son de las editoriales Santillana y Norma, editoriales que tienen una mayor participación, tanto en colegios públicos como privados en el área de Historia, Geografía y Economía. En el caso de Santillana se trabajará con Hipervínculos (2011) e Historia, geografía y economía (2012), y en Norma con Construyendo juntos (2009). Los manuales escolares investigados serán los de tercer y cuarto año de educación secundaria.

* Universidad Nacional Mayor de San Marcos, Lima, Perú. Correo electrónico: jotache5@hotmail.com 
La forma en que analizaremos los manuales escolares será tomando en cuenta la intencionalidad de las editoriales, vinculándola con la reglamentación de los enunciados curriculares, la intervención estatal administrativa y política. Estudiaremos también la sistematicidad en la exposición de los contenidos, tomando en consideración la combinación de textos, imágenes y fuentes. De forma a complementaria a estos objetivos articularemos el discurso difundido por los textos escolares con la producción historiográfica más reciente, para observar la distancia que existe entre una y otra, brecha que al ser tan grande ha dejado de lado a los actores subalternos impidiendo que se convierta en factor para la integración del país, por ello habría que pensar en una debida contextualización y una reconceptualización histórica discursiva de esta guerra desde la subalternidad.

\section{Comparando textos escolares y las tendencias historiográficas actuales}

Comencemos comparando dos tipos de manuales, el de asignaturas y el de áreas, para observar qué tanto se ha avanzado para una mejor calidad de los textos escolares en la representación e incorporación de los actores subalternos en la guerra del Pacífico. Los textos escolares seleccionados son los ya clásicos de Juan Castillo Morales (s,f), Gustavo Pons Muzzo (s,f) y Plácido Díaz Suárez et al. (2001), cuyos manuales fueron los de mayor venta en el Perú, y los manuales actuales de las editoriales Santillana y Norma.

Una primera diferencia es que los manuales de Castillo Morales, Pons Muzzo y Díaz Suárez et al. respondían a un diseño curricular por asignaturas, en el que el curso de Historia estaba dividido en Historia del Perú e Historia Universal, siendo enseñado de manera independiente. Según el MINEDU (2010: 10) se realizaba poniendo énfasis en la memorización de fechas, personajes y hechos, planteando los conocimientos bajo una visión vertical y rígida, "un conocimiento acabado, con verdades establecidas e incuestionables" (Valle 2009: 130). Era una historia ajena y lejana, donde los hechos aparecían desconectados de la realidad cotidiana, discursivamente de carácter nacional. Era una historia militar, de gobernantes y grandes personajes. La historia universal, de América Latina y del Perú, se encontraba separada, sin integración alguna, impidiendo una debida contextualización. Era una historia abocada al pasado sin conexión con el presente. Estaba basada solo en el texto escolar. Se hallaba desconectada del espacio geográfico sin contexto alguno. Estaba parcelada en el tiempo, en etapas sin ninguna conexión. No se encontraba actualizada con las nuevas investigaciones historiográficas (MINEDU 2010: 10).

Por el contrario, según el MINEDU, el cambio que llevó a cabo al modificar estas asignaturas por Historia del Perú en el contexto mundial permitió a los actuales textos escolares, como los elaborados por Santillana y Norma, estar sujetos a un diseño curricular por áreas ${ }^{1}$-se pasó de Ciencias Sociales (2005) a Historia, Geografía y Economía (2009)-, articulando los conocimientos del área con otras áreas, ejerciendo la interdisciplinariedad, proceso que multiplicaba las posibilidades de lograr aprendizajes significativos y desarrollar una formación integral en los estudiantes. Lo que se buscaba era la reflexión y comprensión de procesos históricos. Vincular la vida cotidiana personal y social. Desarrollar un sentido de pertenencia en el alumno. Brindar una imagen de historia local y regional, contribuyendo a la construcción y forja de la nación. Conectar la historia del Perú, de América Latina y del mundo con sentido articulador. Construir la noción de tiempo histórico vinculando el pasado, presente y futuro en un devenir continuo. Motivar al estudiante a manejar y elaborar fuentes, además de los textos de aula y biblioteca. Tener una visión de continuidad en los procesos y análisis de cambios y permanencias. Vincular el mundo académico y la investigación (MINEDU 2010: 10). Si bien el cambio fue importante, los logros respecto del aprendizaje fueron poco significativos en la medida en que "son falencias de la perspectiva con la que la Historia se aborda y no van a variar porque se plantee una enseñanza por áreas en la que se cambia el nombre de Historia por Historia del Perú en el contexto mundial" (Valle 2009: 131).

Otra diferencia eran las actividades, en los manuales por asignatura las asignaciones para los alumnos se dividían en cuestionarios, trabajo práctico y vocabulario, "la mayoría de cuyas respuestas se ubicaban en el libro enfatizando las actividades memorísticas. Bajo esta concepción, un buen libro tenía toda la información [...] poseían además una buena narración" (Aburto 2009: 343). En los textos de Santillana y Norma, que son de carácter colectivo, apoyado por un grupo de especialistas externos y multidisciplinario, como señala Augusta Valle (2011), se pueden distinguir entre otras actividades 
las desarrolladas a partir de las fuentes o fuera de ellas. Las que no están vinculadas directamente a las fuentes son las que buscan la reflexión, la información adicional, la comprensión lectora literal, la comprensión lectora inferencial, la relación con el contenido, la comparación y contraste temático, la imaginación de una situación y la redacción de un texto. Las que están vinculadas directamente con las fuentes son las que buscan la identificación con la postura del autor, la comparación y contraste de posturas, la evaluación de las fuentes, la solución de un problema de investigación, la redacción de un ensayo. Nuevamente, a pesar de este cambio cualitativo se cayó una vez más en el memorismo, no permitiendo el desarrollo del pensamiento crítico de "una herramienta mental potencialmente generadora de nuevos conocimientos" (Trepat 1996: 24).

La extensión de los libros también es una importante distinción, ya que los textos de Juan Castillo Morales (s/f) y Gustavo Pons Muzzo (s/f) al ser por asignaturas eran bastante voluminosos. En cambio, los textos de las editoriales Santillana y Norma al ser por áreas tienen que desarrollar de forma integrada una variedad de asignaturas: Historia, Geografía y Economía, en menos espacio con mayor cantidad de contenidos.

Señalemos algunas características de los textos de Juan Castillo Morales en relación con la guerra del Pacífico, al respecto Cecilia Israel La Rosa sostiene que:

La narración está diseñada para que sea leída únicamente por personas de nacionalidad peruana. El mundo se reduce al escenario nacional.

Versiones de historiadores peruanos y algunos chilenos, siempre destacando valores por el lado peruano (caballerosidad).

Una visión de la historia de este momento limitada a los acontecimientos entre Perú, Bolivia y Chile. Sin mencionar el rol que jugaron los habitantes de la zona fronteriza de estos tres países y del papel que desempeñaron los ingleses. Para ilustrar esto: en Tarapacá trabajaban y vivían juntos en campamentos ciudadanos bolivianos, peruanos y chilenos.

Hay una tendencia a relacionar salvajismo, barbarie, superioridad, poderío con Chile y sacrificio, entrega, orgullo, pundonor, inferioridad con el Perú.
Ciertos pasajes de combates o batallas son narradas épicamente, como una novela (Israel La Rosa 2009: 24-25).

En el manual de Gustavo Pons Muzzo (s/f), la misma autora menciona que:

En general, se puede apreciar que el capítulo de la guerra con Chile está plagado de adjetivos despectivos y subjetivos, que lo único que crean en el estudiante es una conciencia antichilena.

Además se incentiva una conciencia de pérdida, de dolor, de víctima en el peruano, que es sumamente delicada en la formación del ciudadano, quien no desarrolla un sentido crítico para entender la derrota militar (Israel La Rosa 2009: 26).

Además se trascriben fuentes primarias de arraigado sentido nacionalista y antichileno, sin solicitar al alumno ningún tipo de actividad particular. Por último, las asignaciones para los alumnos se dividen en cuestionarios, trabajo práctico y vocabulario. En relación con las preguntas del cuestionario, ellas también son marcadamente nacionalistas y antichilenas, e indagan respecto de acciones heroicas, expresión de valores, desarrollo de combates y batallas, etc. Entre los trabajos prácticos se pide, por ejemplo, dibujar mapas y croquis relativos a las fronteras que tenían Chile, Perú y Bolivia antes del conflicto, marcar los sitios donde se realizaron los principales hechos de la campaña marítima y terrestre, elaborar biografías de los héroes más destacados, enjuiciar algunos hechos ocurridos durante la guerra, como el accionar de presidentes como Prado, Piérola, Iglesias y de héroes: Grau, Bolognesi, Cáceres. Finalmente, respecto del vocabulario los términos que se presentan son en su mayoría de carácter militar: estandarte, recluta, acorazado, campaña, milicia, parapeto, etcétera.

En las editoriales Santillana y Norma si bien se "ha dejado de lado muchos de los adjetivos al referirse a los chilenos dentro del tema de la guerra de 1879-1883" (Israel La Rosa 2009: 16), aún falta mucho por avanzar

debido a la limitada capacitación que reciben los maestros en materia de textos escolares y al escaso tiempo que dedican a reflexionar 
sobre las posibilidades de estos últimos, el aprovechamiento de dichos materiales en las aulas de las escuelas estatales del Perú se ve seriamente limitado. Los libros de texto son utilizados de forma fragmentaria e inadecuadamente integrada con la sesión de aprendizaje en su conjunto (Eguren et al. 2005: 96).

A estas limitaciones por incorporar a los actores subalternos como protagonistas del hecho histórico desarrollando su propia capacidad de agencia (Pereyra 2010: 6), habría que agregarle el desfase que hay entre el discurso que emerge de los textos escolares y la producción historiográfica. Entre las décadas de 1960 y 1970 se produjeron importantes cambios en la historiografía peruana que replantearon la historia del Perú, haciendo su aparición la llamada Nueva Historia.

Los Nuevos Historiadores estuvieron influenciados por una mezcla ecléctica de perspectivas teóricas importadas, que incluyen el marxismo althusseriano, la Escuela de los Annales, la historia social inglesa, especialmente los trabajos de Edward P. Thompson, y, quizás mucho más significativamente, la teoría de la dependencia y el estructuralismo. Al mismo tiempo, encontraron en los trabajos de José Carlos Mariátegui un marco conceptual explicatorio considerablemente autónomo y original de la historia y sociedad peruana (Drinot 2008: 236).

La Nueva Historia desarrolló una visión bastante crítica de la realidad peruana, Portocarrero y Oliart (1989) la denominaron "idea crítica", en la que "si bien han participado historiadores, ha sido obra directa de los maestros de escuela" (Flores Galindo 1988: 67). La idea crítica brinda una imagen de la historia peruana "dominada por el signo de la frustración, y su narración es el relato de grandes injusticias, de episodios traumáticos y de esperanzas frustradas" (Portocarrero y Oliart 1989: 103). Esta forma de ver la historia contrastaba con la "idea oficial" dominante en el sistema educativo peruano y principalmente en sus textos escolares, que difundía la idea oficial un "nacionalismo complaciente que sobrevalúa la integración social y que considera la explotación y el abuso como supervivencias llamadas a desaparecer" (Portocarrero y Oliart 1989: 104). Esta historia tradicional se caracteriza por la marginación de los sectores subalternos y de las regiones, resaltando los grandes personajes y los acontecimientos políticos y militares.

Así, a pesar de la persistencia de la versión tradicional de la historia peruana en los libros de texto, lo que los alumnos de escuela [...] aprenden de sus maestros y profesores no corresponde necesariamente a lo que encuentran en sus libros. En la escuela [...] los peruanos se ven expuestos a una esquizofrenia historiográfica. La historia peruana, tal como es enseñada a la mayoría de los peruanos [...] consiste en dos metanarrativas contradictorias y en gran parte negativas, que poco tienen que ver con la historiografía [más reciente] y que no estimulan el desarrollo intelectual ni invitan a una reflexión crítica. Así, no es de sorprender que la mayoría de los peruanos desarrollen una conciencia histórica que además de ser, por lo general, negativa en su proyección, no logra prepararlos para entender el mundo en el que viven ni ayudarlos a desarrollar un espíritu crítico (Drinot 2006: 10).

Esta conciencia histórica esquizofrénica llevada a la guerra del Pacífico confronta dos metanarrativas que no se dan, como señala Drinot, entre los profesores de colegio y los textos escolares, estos por el contrario tienen como características ser complementarias y reduccionistas aunque con diversos niveles de intensidad. Se podría sostener que "conscientes o no ambos discursos generan visiones históricas negativas y egos nacionales esmirriados que se traducen en comportamientos cotidianos irresueltos en donde se traducen visiones del pasado conflictivas y segregadoras" (Betalleluz 2003: 227). La contradicción estaría con la reciente producción historiográfica en ambos países que está buscando descentrar las relaciones peruano-chilenas disminuyendo el peso que tiene la guerra del Pacífico en la historia de ambos países, ampliando para ello los tiempos históricos, expandiendo los espacios geográficos de interacción, diversificando los actores sociales hacia la subalternidad, apostando por la integración binacional con una visión globalizada de la historia ${ }^{2}$. 
Gran parte de esta nueva producción busca superar algunas de las premisas que guiaron los primeros estudios nacionalistas y marxistas de la guerra, en particular de que la guerra podía ser entendida en términos de victimarios y víctimas. La nueva literatura está menos interesada en aproximarse al estudio de la guerra como un diagnóstico de las deficiencias del Estado-Nación peruano. Los intentos por escribir historias de la guerra que tienen en consideración perspectivas binacionales e incluso multinacionales son cada vez más comunes (Drinot 2013: 50).

La forma en que ha sido abordada la guerra del Pacífico en los textos escolares ha impedido que sea un factor para la integración de ambos países y para el desarrollo de una cultura de paz, por ello habría que pensar, como alternativa, una debida contextualización y una reconceptualización discursiva e histórica de la guerra del Pacífico, que enfrente y no evite el conflicto, tomando la variante multicultural del discurso nacional que institucionalmente está impulsando el Estado (Smith 2010: 53-54), reconociendo la contribución de los actores subalternos de ambos países en la guerra, los que si bien no hablan, el hecho de ser silenciados no significa que no existan (Spivak 2003). También se debería impulsar una didáctica de la guerra que enseñe para la paz, donde las visiones de los mismos hechos se multipliquen (Mondaca et al. 2013: 133), además, se deben exaltar los aspectos históricos comunes y positivos, incluyendo los de larga, mediana y corta duración en el tiempo (hitos históricos) y el espacio (territorios transfronterizos), mediante el desarrollo del pensamiento crítico, fortaleciendo la confraternidad. Para ello es necesaria una reevaluación de los manuales escolares y un mayor acercamiento a la labor desempeñada por los historiadores de ambos países que promueven una historiografía a favor de la integración.

\section{Manejo de la información en los textos escolares}

Se tiende a considerar que los contenidos de los manuales escolares son algo que no debe ser sometido a crítica, encontrándose en ellos seguridad y garantía de profesionalismo (Díez Gutiérrez 2011). Desde un enfoque crítico todos los contenidos de los textos escolares son provisionales, en constante discusión y revisión, y cargados de la ideología que subyace a sus editores y al contexto histórico-social de su producción. El análisis de contenido toma prestados aspectos esenciales del enfoque crítico del discurso, este es un producto "susceptible de revelar determinados contenidos subyacentes (visiones del mundo, opiniones, ideologías)" y un instrumento "capaz de proyectar esos contenidos en las representaciones sociales o individuales de las personas" (Díez Gutiérrez 2011: 96).

La información que aparentemente debería ser confiable y razonada, expuesta de forma coherente, rigurosa, original y relevante, está marcada por el nacionalismo multicultural excluyente, sobresaliendo la figura del héroe donde "casi todos son hombres, blancos, viejos, militares y criollos" (Fonseca 2009: 337). Todo ello ha generado una imagen excluyente y marginadora de nuestra conciencia nacional, habría que reconceptualizar la heroicidad de forma más pluralista e inclusiva, donde la "figura del indígena, del negro, de la mujer, del joven, del civil, etc., deben ser incluidas como paradigmas esenciales de civilidad, ya que de esa manera acercamos mucho más la reflexión histórica al auténtico rostro de nuestros pueblos" (Fonseca 2009: 337).

La apertura de los textos escolares a los nuevos enfoques brindados por los estudios subalternos nos permitiría cambiar las miradas dicotómicas y excluyentes de estos grupos que se tienen tanto en Perú como en Chile, por una imagen más autocrítica e integrada que tome en cuenta la participación activa de los actores subalternos. Partiendo de la idea de que la guerra del Pacífico fue provocada por las elites, es importante recoger la voz de esos otros que no la tuvieron y que participaron activamente en el desarrollo de este conflicto bélico. Se reintroduce así nuevamente el rol activo y creador de los sujetos históricos en la construcción de su propia historia. El discurso de la "historia nacional" no basta para explicar los procesos particulares de estos grupos durante la guerra del Pacífico ${ }^{3}$. Lastimosamente las pocas apariciones de los actores subalternos en los libros de texto de Norma y Santillana están plagadas de una retórica que exalta desde el punto de vista nacionalista la entrega, orgullo, pundonor del peruano no del subalterno como sujeto histórico activo. La condición subalterna aparece cosificada como "participación popular" mediante acciones de defensa como reservistas, montoneras o rabonas, 
convirtiéndose, como dice Rocío Silva Santisteban (2006: 136), en "un significado sin significante". Si bien reconocen alguna contribución de los sectores subalternos principalmente indígenas en la guerra, son excluidas las temáticas étnicas y raciales (Smith 2010). Otros grupos como los chinos y los negros son dejados de lado en la narrativa bélica.

Hay una escasa extensión y profundidad de los contenidos y falta de equidad en el tratamiento de los mismos. La forma en que se elabora el contenido de los manuales escolares de Norma y Santillana se inclina a un tratamiento del conocimiento más didáctico que epistemológico, incluso la diagramación tiende a facilitar más el aprendizaje que a profundizar el conocimiento. La edición de cada manual escolar está muy pensada, su diseño y composición responden a un trabajo riguroso y pormenorizado, que no deja nada prácticamente al azar (Díez Gutiérrez 2011). Las supuestas "lagunas históricas" no son inocentes, se observa una preocupación por no olvidar determinados hechos de la memoria histórica, como el accionar de los grandes personajes en la guerra del Pacífico. Los textos escolares que reflejan la historia oficial han cumplido en el devenir histórico diferentes funciones que van desde contribuir a la invención de la nación, el imponer o armonizar intereses políticos y sociales, hasta fortalecer el nacionalismo (Espinoza 2012). En su relato de la guerra "ocultan u obvian las investigaciones que no contribuyen a alimentar sus posiciones políticas" (Rodríguez 2009: 174). Con estas limitaciones "el subalterno no puede expresarse por sus formas de representación; es decir, no puede valerse por sí mismo ni puede difundir sus creencias, sus propios conocimientos o su forma de ver el mundo" (Pereyra 2010: 5).

La forma en que acabó el conflicto en 1883, y hasta 1929, casi 50 años después cuando se produjo la separación de Tacna y Arica, es lo que ha marcado totalmente a los peruanos, siendo más difícil asumir el discurso del perdedor frente al vencedor. Los chilenos han olvidado "más rápidamente" lo sucedido en la medida en que vencieron la guerra. Por ello miran más hacia el futuro, mientras que los peruanos, al haber sido derrotados, se detuvieron en el pasado, siendo su peso más marcado. La significación de la historia se hace a partir de pasados decimonónicos bélicos heroizados, los héroes nacionales más representativos no son los de las guerras de Independencia sino de la guerra del Pacífico, una guerra en la que se perdió. Mediante nuestras indagaciones observamos que el personaje con la mayor cantidad de monumentos construidos en el Perú a lo largo de la historia es Francisco Bolognesi, mientras que el personaje declarado figura del milenio fue Miguel Grau. Ello debido al peso que tiene la defensa del territorio y la imagen de los héroes por acción de un Estado que se encuentra atado a conceptos propios del siglo XIX, el que asume que debe velar por la soberanía territorial, pensar por el ciudadano en aras de este objetivo y para ello tiene que construir una historia oficial en términos nacionalistas (Cavieres 2013), todo ello se encuentra proyectado en los manuales escolares. La política de inclusión y pluralidad impulsada por el Estado cuando tiene que abordar las relaciones peruano-chilenas en general y la guerra del Pacífico en particular se torna limitadora y excluyente de los sectores subalternos.

Complementemos lo sostenido hasta aquí con una cuestionable encuesta elaborada por Wilfredo Kapsoli (2001), en la que buscaba indagar respecto de la percepción acerca de la historiografía peruana que tienen los estudiantes de la carrera de Educación de cinco universidades públicas: José Faustino Sánchez Carrión de Huacho, Daniel Alcides Carrión de Cerro de Pasco, San Agustín de Arequipa, y Enrique Guzmán y Valle "La Cantuta" y San Marcos de Lima ${ }^{4}$. Cuando se les pidió a los 224 encuestados ponerle una nota en la escala de uno al diez a las diferentes "tendencias historiográficas y corrientes de pensamiento", los estudiantes dieron la media más alta al materialismo histórico $(7,26 \%)$, seguido del estructuralismo $(6,19 \%)$, la "Ilustración" (6,16\%), el funcionalismo $(5,77 \%)$, el (neo) positivismo $(5,45 \%)$ y la Escuela de los Annales (4,40\%). Esto le hace concluir a Kapsoli que "en las universidades públicas no se ha perdido la conciencia crítica a pesar del avasallamiento de ideologías adormecedoras y los intentos de despolitización de la sociedad" (Kapsoli 2001: 85-86). Paulo Drinot piensa, por el contrario, que

las respuestas reflejan, en parte, los problemas conocidos que enfrentan las universidades públicas, producto de presupuestos escuetos, lo que impide la compra regular de nuevos libros. Pero también reflejan el hecho que muchos profesores de historia hacen poco por incorporar nuevas 
perspectivas historiográficas o actualizar sus currículas (Drinot 2006: 16).

Cuando se les pidió responder pertinente a hechos y personajes históricos, la época más importante de la historia del Perú había sido el periodo prehispánico $(27,7 \%)$, seguido por la Independencia $(13,8 \%)$. En contraste, "la época más dramática de la historia peruana" había sido el periodo "colonial" (18,3\%), "Guerra con Chile" $(15,6 \%)$ y "crisis actual" $(12,5 \%)$. Preguntados respecto de los "héroes fundamentales del país", los estudiantes eligieron a Miguel Grau (33,5\%), seguido de Túpac Amaru II (11,6\%). Paulo Drinot (2006) concluye de forma contundente:

\begin{abstract}
Basándose en fundamentos historiográficos vetustos y excesivamente simplificados, tanto los profesores universitarios como los alumnos parecen estar reproduciendo una visión simplista y maniquea del pasado que incorpora elementos tanto de la perspectiva tradicional nacionalista como de la idea crítica. El resultado es una manera de pensar la historia que impide el análisis crítico: la historia se enseña como dogma (Drinot 2006: 17) .
\end{abstract}

Si bien en los textos escolares los aspectos "nacional-heroizadores" han disminuido, ampliándose la presencia de los aspectos de vida cotidiana y colectivos sociales, la presencia de los actores subalternos en la guerra del Pacífico aún es escasa. En el uso de imágenes predominan las de personajes y mapas, utilizadas con una función nacionalista principalmente más decorativa y emotiva, estética y motivadora que informativa y explicativa (Valls 2007), estando dependientes y subordinadas al conjunto del texto escolar, no aportando nuevos elementos significativos. Es recurrente en ambas editoriales colocar la pintura de Francisco Fierro $E l$ soldado y la rabona y el cuadro de Ramón Muñiz El repase o un mapa del accionar de las montoneras en la campaña de La Breña. En la medida en que no son analizadas adecuadamente como un documento histórico, y a que aparecen como ilustraciones en las que se coloca el nombre de los personajes o acontecimientos representados, los que ya han sido citados o descritos de forma breve en el texto escrito, provocan comprensiones anacrónicas de los hechos (Valls 1999). Es importante, desarrollar una capacidad crítica y analítica respecto de las imágenes, más aún debido al peso que tienen en las sociedades de la información.

Los textos escolares también han incorporado una variedad de fuentes escritas, estas requieren un marco teórico adecuado para poder usarlas, que va desde la clasificación, análisis, identificación de la postura, evaluación y uso final por parte del alumno. Como indica Augusta Valle (2011), el trabajo con fuentes es una importante oportunidad para el desarrollo del pensamiento crítico, en la medida en que lleva a los estudiantes a emplearlas para solucionar un problema con sus propios argumentos. Respecto de su uso, predominan las fuentes secundarias sobre las primarias, en ellas no se observa el empleo de métodos de comparación y contraste de posturas, lo que impide distinguir las similitudes y diferencias en la perspectiva de la fuente, perdiendo así la posibilidad deconstruccionista de recuperar "la prosa de la contrainsurgencia" (Guha 1999). Las fuentes históricas son empleadas no para desarrollar pensamiento crítico, analizándolas y evaluándolas de forma reflexiva y estimulante, sino para la comprensión lectora (Valle 2009). Cuando se trata de actores subalternos es el historiador por medio de la fuente secundaria quien habla por él.

Así, en contenido informativo, imágenes y en el uso de fuentes se observan en los textos escolares relaciones de saber y poder (Palacio y Ramírez 1998) estando sujetos al currículo, criterios didácticos, reglamentaciones del MINEDU, ideas de los autores, informes de mercado, exigencias de los maestros, que actúan como líneas fuerza, imponiéndose unos a otros, entremezclándose, refundiéndose entre sí, de todo esto sale un texto desarticulado que lleva a la "discriminación, las ausencias [lo que no conviene mencionar o mostrar], la manipulación, las imposiciones" (Soaje-de Elías 2012: 33), donde es necesario resaltar más las acciones heroicas de los grandes personajes que los actores subalternos, bajo la premisa de buscar reforzar la identidad nacional y la formación ciudadana, la que termina exaltando el patriotismo. Charles Walker señala al respecto que:

Libros de texto que cuestionen figuras patrióticas como Castilla o Grau también generarían protestas. Mientras el "pensamiento progresista" [desde posturas cercanas a la izquierda hasta las visiones seculares 
de la historia y del Estado] domina en las Ciencias Sociales en el Perú, no ocurre lo mismo entre los sectores que supervisan la producción y, más importante aún, los que compran los libros de texto (Walker 2009: 410).

Hay que reenfocar estos conflictos desde perspectivas más sociales, uniendo la representación con el comportamiento de los individuos, rescatando acercamientos y solidaridades. Revalorizar los procesos sociales reordenando los elementos históricos, adecuándolos a sus propias dimensiones temporales. Realizar ese ejercicio observando los impactos concretos respecto de los actores subalternos, la sociedad civil y sus familias, vencedores y vencidos, los protagonistas reales, cambia en mucho los balances oficiales de los conflictos que resalta las acciones bélicas y lo confrontacional (Chaupis Torres y Vito, 2013). Como señala Manuel Burga en torno a la pregunta ¿para qué aprender historia en el Perú?

La razón es muy sencilla: necesitamos librarnos, casi con urgencia, de una pesada carga histórica y construir una memoria sana que nos permita repensar nuestro pasado, mirarnos a nosotros mismos sin complejos y enfrentar más conscientes y decididos los retos que nos depara el futuro (Burga 2005: 52).

Aplicando esta idea a las relaciones peruanochilenas nos sería de mucha utilidad, para apreciarnos mejor y poder superar el complejo de la derrota, conocer mejor el presente, preparándose para afrontar el futuro con un adecuado diálogo con el pasado; aproximarnos a la objetividad histórica para a partir del pasado vislumbrar el futuro asumiendo un compromiso con el devenir de la historia peruana; construir una memoria que integre y construya, olvide los traumas y recuerde los hechos positivos del pasado (Burga 2005).

\section{Conclusiones}

El presente trabajo tuvo como objetivo analizar el papel desempeñado por los actores subalternos en la guerra del Pacífico a partir de la forma como han sido presentados en los textos escolares de las editoriales Norma y Santillana, y lo que se observó fue que tienen serias deficiencias para alcanzar la integración multicultural y una cultura de paz. No se logra formar estudiantes que puedan resolver conflictos de forma pacífica y vivir en democracia. La autoestima patriótica que exaltan no va articulada a una estima por el otro subalterno que terminan siendo silenciados. La condición subalterna aparece cosificada como "participación popular" mediante acciones de defensa como reservistas, montoneras o rabonas, destacándose la entrega, orgullo, pundonor del peruano no del subalterno como sujeto histórico activo.

Las competencias planteadas por el MINEDUC, como el manejo de información, terminan siendo la expresión de la historia oficial elaborada por un Estado que se encuentra atrapado en el siglo XIX, con una visión nacionalista que carga con el pasado histórico, teniendo el deber de defender a los ciudadanos y la soberanía territorial. Los actores subalternos aparecen durante la guerra del Pacífico cargados de imágenes que no reivindican su capacidad de agencia, impidiendo el desarrollo de un pensamiento crítico libre de prejuicios y estereotipos. Un primer paso sería integrar el área de Formación Ciudadana y Cívica a la de Historia, Geografía y Economía, para una adecuada construcción de la cultura cívica y ejercicio ciudadano basada en valores y participación democráticos respetuosos del otro. Un segundo paso sería el incorporar el tema de la integración binacional en la currícula escolar, lo que obligaría a capacitar a los docentes y elaborar materiales de enseñanza basados en la integración que reconozca la multiculturalidad. Un tercer paso sería diseñar una currícula común para ambos países donde el peruano conozca la historia de Chile y el chileno conozca la historia de Perú, ya que solamente conociendo al otro se pueden generar alteridades positivas. 


\section{Referencias Citadas}

Aburto, C.

2009 Conocimiento histórico y divulgación del conocimiento histórico: a propósito de la elaboración de textos escolares. En Las independencias desde la perspectiva de los actores sociales, compilado por J. L. Orrego et al., pp. 341-350. Organización de Estados Iberoamericanos / Universidad Nacional Mayor de San Marcos / Pontificia Universidad Católica del Perú, Lima.

Betalleluz, B.

2003 La imagen de la historia nacional peruana. Hispanistas, indigenistas y marxistas. Periodificaciones, proyectos y propuestas de la historiografía peruana del siglo XX. Revista Diálogos, 7: 219-234.

Burga, M.

2005 La historia y los historiadores en el Perú. Universidad Nacional Mayor de San Marcos / Universidad Inca Garcilaso de la Vega, Lima.

Castillo Morales, J.

Historia del Perú en el proceso americano y mundial 4. Lima: Bruño.

Cavieres, E.

2013 Conversaciones en Lima: la historia como instrumento de integración chileno-peruana. Ediciones Universitarias de Valparaíso, Valparaíso.

Cavieres, E. y Aljovín, C. (eds.).

2006 Perú-Chile/Chile-Perú 1820-1920. Desarrollos políticos, económicos y sociales. Universidad Nacional Mayor de San Marcos / Convenio Andrés Bello / Pontificia Universidad Católica de Valparaíso, Lima.

Chaupis Torres, J. y Vito, J.

2013 Sobre los historiadores y la historiografía. En Conversaciones en Lima: la historia como instrumento de integración chileno-peruana, editado por E. Cavieres, pp. 47-65. Ediciones Universitarias de Valparaíso, Valparaíso. Chávez García, T.

2006 La enseñanza de la historia del Perú en la educación secundaria durante la segunda mitad del siglo XX. Pontificia Universidad Católica del Perú, Lima.

Díaz Suárez, et al.

2001 Historia del Perú en el proceso americano y mundial 4. Escuela Nueva, Lima.

Díez Gutiérrez, E. J.

2011 Análisis de los textos escolares de historia. Estudio de caso sobre la posguerra civil española. Revista Historia de la Educación Latinoamericana, 16: 87-118.

Drinot, $\mathrm{P}$.

2006 Historiografía, identidad historiográfica y conciencia histórica en el Perú. Universidad Ricardo Palma, Lima.

Drinot, $\mathrm{P}$.

2008 Después de la Nueva Historia: Tendencias recientes en la Historiografía Peruana, Illapa, 2: 235-255.

Drinot, $\mathrm{P}$.

2013 Ciberlugar de memoria: la Guerra del Pacífico (1879-1884) en la era global de YouTube. Hueso Humero, 60: 43-69.

Eguren, M. et al.

2005 Recursos desarticulados. El uso de textos en la escuela pública. Instituto de Estudios Peruanos, Lima.

Espinoza, A.

2012 La independencia en los textos escolares peruanos, 1821-c. 1921. En el nudo del imperio. Independencia y democracia en el Perú, editado por C. McEvoy, pp. 395416. Instituto de Estudios Peruanos / Instituto Francés de Estudios Andinos, Lima.

Flores Galindo, A.

1988 La imagen y el espejo: la historiografía peruana (19101986), Márgenes, 2 (4): 55-83.

Fonseca, J.

2009 Recomendaciones para la elaboración de textos esco-

lares con enfoque en la historia latinoamericana. En Las independencias desde la perspectiva de los actores sociales, compilado por J. L. Orrego et al., pp. 335-340. Organización de Estados Iberoamericanos / Universidad Nacional Mayor de San Marcos / Pontificia Universidad Católica del Perú, Lima.

Guha, R.

1997 La prosa de la contrainsurgencia. En Debates postcoloniales: una introducción a los estudios de la subalternidad, compilado por S. Rivera Cusicanqui y R. Barragán, pp. 33-72. Historias / Aruwiyiri / SEPHIS, La Paz.

Israel la Rosa, C.

2009 Formación de valores a través de textos escolares en la Guerra del Pacífico. Desde el Sur, 1: 15-30.

Kapsoli, W.

2001 Paradigmas de la historiografía peruana. En Historia $e$ historiadores, compilado por W. Kapsoli, pp. 65-100. Universidad Ricardo Palma, Lima.

Loayza, A.

2011 Introducción: notas sobre la historiografía en la Universidad San Marcos después de la Nueva Historia. En Trabajos de historia. Religión, cultura y política en el Perú, siglos XVII y XX, editado por D. León, et al, pp. 13-34. Universidad Nacional Mayor de San Marcos, Lima.

Ministerio de Educación del Perú

2010 Orientaciones para el trabajo pedagógico. Área de Historia, Geografía y Economía. Lima.

Mondaca Rojas, C.; Rivera Olguín, P.; Aguirre Munizaga, C.

2013 La escuela y la Guerra del Pacífico. Propuesta didáctica de historia para la inclusión educativa en contextos transfronterizos del norte de Chile. Si Somos Americanos. Revista de Estudios Transfronterizos. 23 (1): 123-148.

Norma

2009 Construyendo juntos 3. Lima.

Palacio, L.V. y Ramírez, M.L.

1998 Reflexiones sobre el texto escolar como dispositivo. Revista educación y pedagogía, 10 (21): 217-235.

Parodi, D. y González, S (eds.)

2014 Las historias que nos unen. Episodios positivos en las relaciones peruano-chilenas siglos XIX y XX. Universidad Arturo Prat / RIL, Santiago.

Pereyra Chávez, N. E.

2000 La historiografía de la subalternidad y la historiografía peruana: un necesario balance. Summa Humanitatis 4 (1): $1-23$.

Pons Muzzo, G.

Historia del Perú 3. Universo, Lima.

Portocarrero, G. y Oliart, P.

1989 El Perú desde la escuela. Instituto de Apoyo Agrario, Lima.

Rodríguez, J.J.

2009 Construyendo al enemigo: Falacias y verdades en la construcción del nacionalismo a través de los textos escolares en el tema de la Guerra del Pacífico. Illapa, 4: 173-188. 
Santillana

2011 Hipervínculos 3. Lima.

Santillana

2012 Historia, Geografía y Economía 4. Lima.

Soaje-de Elías, R.

2012 Estudio de los textos de Historia y de Ciencias Sociales chilenos entre 2000 y 2010. Educ.Educ., 15 (1): 23-41.

Smith, S.

2010 Manuales escolares de Historia y Ciencias Sociales y subalternidad mapuche en un Chile multicultural. Tinkuy, 12: $53-72$.

Spivak, G. Ch.

1998 ¿Puede el subalterno hablar?. Revista Colombiana de Antropología, 39: 297-364.

Trepat, C.

1996 Procedimientos en historia. Aula de innovación educativa, 56: 23-27.

Valle, A.

2009 El trabajo con fuentes y el desarrollo del pensamiento del pensamiento crítico. Seminario internacional: Textos escolares de historia y ciencias sociales. pp. 129-149, Ministerio de Educación de Chile, Santiago.
Valle, A.

2011 El trabajo con fuentes y el desarrollo del pensamiento crítico. Educación, 20 (38): 81-106.

Valls, R.

1999 Sobre la selección y uso de las imágenes de los manuales escolares de historia: un ejemplo español (1900-1998). Clío y Asociados. La Historia Enseñada, 4: 77-100.

Valls, R.

2007 Las imágenes en los manuales escolares de historia y las dificultades de su uso didáctico. Clío y Asociados. La Historia Enseñada, 11: 11-23.

Walker, $\mathrm{Ch}$

2009 La nueva historia y la historia de siempre: el impacto de las nuevas corrientes historiográficas en el Perú actual. En Diálogos con el Perú. Ensayos de historia, editado por Ch. Walker, pp. 390-418. Pedagógico de San Marcos, Lima.

Walker, Ch.

2012 Retos y posibilidades. La historia en el Perú actual. Libros y Artes, 11 (54-55): 20-23.

\section{Notas}

1 Su antecedente sería la reforma educativa que llevó a cabo el régimen fujimorista durante la década de 1990, la que como indica Teresa Chávez García (2006) buscaba resaltar la necesidad de fortalecer los valores cívico-ciudadanos, el desarrollar una cultura de paz y el estudio de las ciencias sociales como base para la forja de la identidad nacional. Lastimosamente no se lograron estos objetivos, ya que se redujo el tiempo de estudio asignado a la historia, no se capacitó debidamente a los docentes en la nueva metodología, ni se brindó a las instituciones educativas el material didáctico necesario para modernizar la enseñanza de la historia (Chávez García, 2006: 157).

2 Es importante destacar las diversas publicaciones del historiador chileno Eduardo Cavieres, y una en particular, la que realizó conjuntamente con el historiador peruano Cristóbal Aljovín en el 2006. Ambos autores coordinaron un proyecto que reunió a historiadores chilenos y peruanos para reflexionar desde una perspectiva regional sobre el desarrollo comparativo de las historias nacionales de Chile y Perú dentro de una estructura cronológica amplia, esta iba desde 1820 hasta 1920, encontrándose en este marco temporal tanto similitudes como diferencias en sus procesos de evolución histórica. También es de destacar los trabajos del historiador peruano Daniel Parodi, y uno en particular, el que realizó conjuntamente con el historiador chileno Sergio González en 2014, en el que participaron investigadores peruanos y chilenos donde sin negar los episodios negativos de ambos países, buscaron resaltar los hechos positivos, esas historias comunes que son dignas de ser recordadas con el objetivo de fortalecer la integración bilateral. Nosotros con el apoyo invaluable de Eduardo Cavieres apostamos por realizar miradas un poco más integradoras sin perder el sentido de crítica que debe tener el estudio de las relaciones peruano-chilenas, de manera particular la guerra del Pacífico, en las que se asuman responsabilidades en torno al conflicto, sea como vencedor o vencido, para así lograr una mayor comprensión del pasado, para que sirva y no divida frente a los requerimientos del presente con una visión de futuro.

En el simposio "Actores subalternos durante la Guerra del Pacífico", que tuve el honor de coordinar en el IX Congreso Internacional de Etnohistoria: colonización, descolonización e imaginarios que se llevó a cabo del 11 al 14 de noviembre de 2014, en Arica, se discutió relativo a los aportes que puede brindar la subalternidad para los estudios de la guerra del Pacífico y para las relaciones peruano-chilenas. Al buscar recuperar a los "otros" indios, chinos, negros, mujeres, jóvenes, etc., como sujetos históricos, una entidad cuya voluntad y razón constituye una praxis de acción desde la relectura de la documentación y los discursos historiográficos que le niegan el poder de agencia. Es así que el simposio buscaba recuperar esas voces más allá de la perspectiva de la nación, para ello se discutió entre los 16 investigadores que participaron de ambos países desde la perspectiva del pasado, pero también del presente, apelando tanto a la historia como a la historiografía, a la fuente de archivo como a la entrevista actual.

4 De las cinco universidades estatales encuestadas por Wilfredo Kapsoli solo dos tienen departamentos de historia, San Agustín de Arequipa y San Marcos de Lima, las tres restantes tienen únicamente departamentos de educación.

5 Estas afirmaciones de Drinot a pesar de ser demasiado generalizadoras y de que demuestran cierto "desconocimiento de la historiografía de las universidades públicas" (Loayza, 2011: 13) es útil para observar la vigencia de imágenes estereotipadas en torno a las universidades estatales en Perú que se reproducen en los círculos académicos. 